\title{
Variation in the Origin of Sternocleidomastoid Muscle. A Case Report
}

\author{
Variación en el Origen del Músculo Esternocleidomastoideo. Reporte de Caso
}

"T. Ramesh Rao; **Vishnumaya, G; **Prakashchandra Shetty, K. \& ***Suresh, R.

\begin{abstract}
RAMESH, R. T.; VISHNUMAYA, G.; PRAKASHCHANDRA, S. K. \& SURESH, R. Variation in the origin of sternocleidomastoid muscle. A case report. Int. J. Morphol., 25(3):621-623, 2007.

SUMMARY: A rare case of additional slip in the origin of the clavicular head of sternocleidomastoid muscle was found during our routine dissection, on both sides of the neck in an elderly male cadaver. However, on both side of the same muscle no such additional slip of origin was found at the sternal head of the sternocleidomastoid near its origin nor at its insertion of the muscle.
\end{abstract}

KEY WORDS: Sternocleidomastoid muscle; Anatomical variation.

\section{INTRODUCTION}

Sternocleidomastoid muscle is present across the side of the neck and forms a prominent landmark when contracted. It originates in two heads, medial sternal head which is rounded and tendinous; and lateral clavicular head. The sternal head originates from the upper part of the anterior surface of the manubrium sterni and ascends posterolaterally. The clavicular head is variable in width and originates from the superior surface of the medial third of the clavicle and ascends almost vertically. The two heads of origin are separated by a triangular interval, which corresponds to a surface depression, the lesser supraclavicular fossa. As they ascend the clavicular head spirals behind the sternal head and blends with its deep surface below the middle of the neck, forming a thick, rounded belly. The muscle is inserted by a strong tendon to the lateral surface of the mastoid process from its apex to its superior border, and by a thin aponeurosis into the lateral half of the superior nuchal line. The clavicular fibres are mainly directed to the mastoid process; the sternal fibres extend to the occipital bone.

The sternocleidomastoid muscle is supplied by the spinal part of the accessory nerve. It also receives proprioceptive innervations by cervical spinal nerves from the cervical plexus.

The sternocleidomastoid muscle receives its blood supply from branches of the occipital and posterior auricular arteries, which supply the upper part of the muscle. The muscular branches coming from the superior thyroid artery and suprascapular artery supply the middle and lower part of sternocleidomastoid muscle.

The sternocleidomastoid muscle acting alone, laterally flexes the neck and rotates the face to the opposite side. The two muscles acting together flex the head and neck forcibly.

Spasm of the sternocleidomastoid muscle, usually of unknown origin but sometimes congenital, is one cause of a flexion deformity of the neck known wryneck or torticollis; other muscles that rotate and flex the neck also may contribute to torticollis (Williams et al., 1995; Standring et al., 2005).

\section{CASE REPORT}

During the gross dissection of an elderly male cadaver a rare case of additional slip of origin was found on both sides, in the clavicular head of sternocleidomastoid muscle (Fig. 1). Because of this additional slip of origin the clavicular head was extending up to the middle of the

\footnotetext{
* Department of Paraclinical Sciences, Faculty of Medical Sciences, The University of West Indies, St. Augustine, Trinidad, West Indies.

** Department of Anatomy, Kasturba Medical College, Manipal - 576104, India.

${ }^{* * *}$ Department of Preclinical Sciences Faculty of Medical Sciences, The University of West Indies, St. Augustine, Trinidad, West Indies.
} 
clavicle on both sides, there by reducing the gap between the trapezius and sternocleidomastoid muscles. The two clavicular heads of origin of sternocleidomastoid muscle were separated by a wider triangular interval (compared to the interval between the sternal head and normal clavicular head), which corresponds to one more surface depression, the additional lesser supraclavicular fossa. The additional slip is also supplied by a branch from the spinal part of the accessory nerve. However, on both sides the origin of sternal head and the insertion of sternocleidomastoid muscle were found to be normal.

\section{DISCUSSION}

The sternocleidomastoid muscle varies much in the extent of its origin from the clavicle. In some cases the clavicular head may be as narrow as the sternal; in others it may be as much as $7.5 \mathrm{~cm}$ in breadth. When the clavicular origin is broad, it is occasionally subdivided into several slips, separated by narrow intervals. More rarely, the sternocleidomastoid and trapezius muscles are fused with each other. Some authors regard this fusion between the

\section{Additional clavicular head}

Additional lesser supraclavicular fossa

Clavicular head

\section{Lesser supraclavicular fossa-}

Sternal head

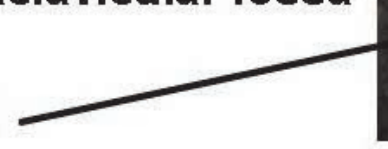

Fig. 1. Variation in the origin of sternocleidomastoid muscle.

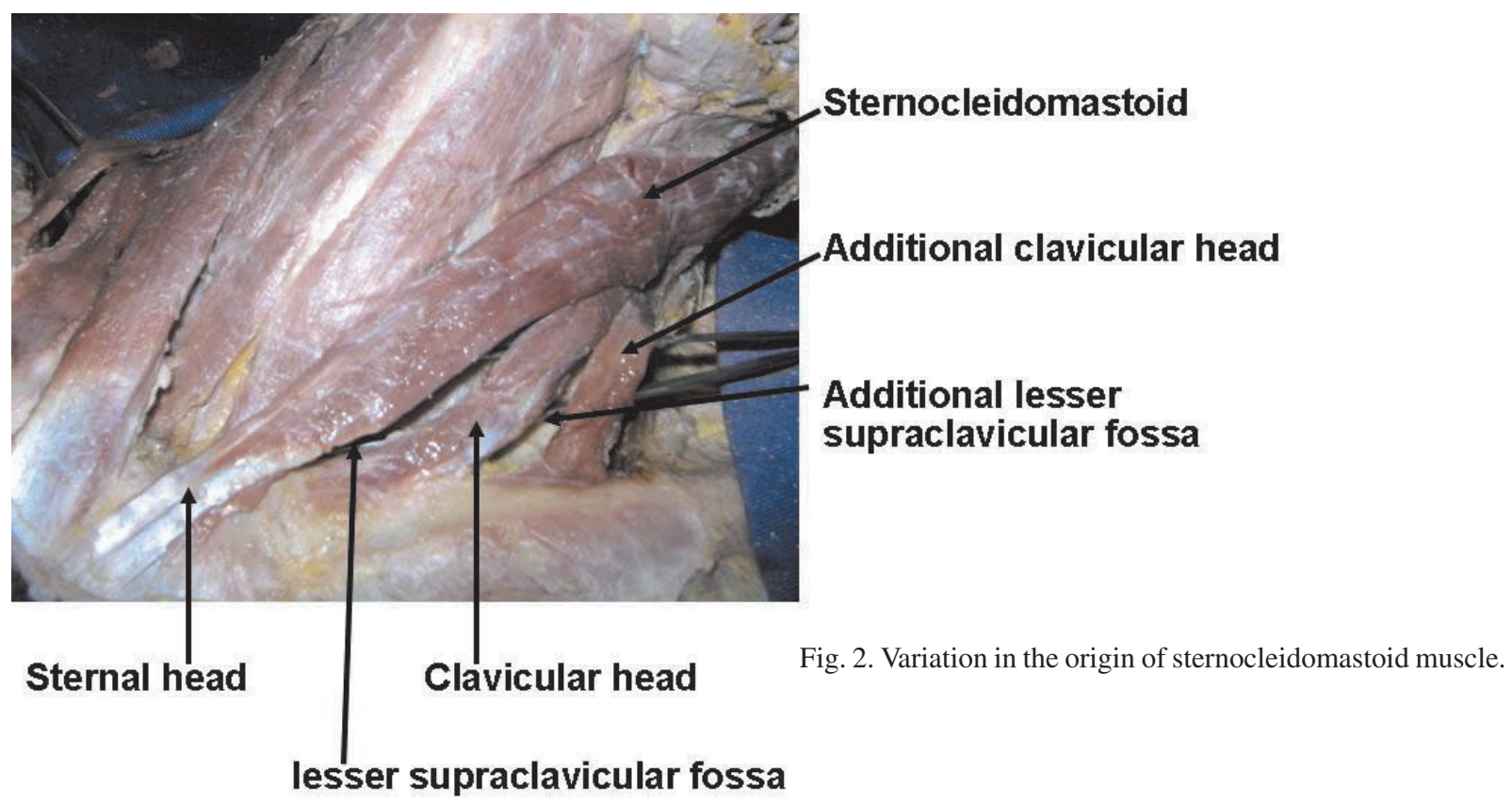


sternocleidomastoid and trapezius muscles as normal (Bergman et al., 1988). This may be due to the developmental reason, since both the muscles are derived from the same source, the post-sixth branchial arch. The sternocleidomastoid muscle frequently separates into other parts, which are arranges in two parts: a superficial sternomastoid, sterno-occipital and cleido-occipital part; and a deep layer consisting of a deep sternomastoid and cleidomastoid part. The names indicate the attachment of various parts. Knowing the 5 parts of the sternocleidomastoid muscle is important for harvesting the muscle flap. A supernumerary cleido-occipital, more or less separate from the sternomastoid has a reported frequency of $33 \%$ (Mustafa, 2006, Bergman et al.).

Occasionally, the lower portion of the muscle is traversed by a tendinous intersection, which may indicate the formation of the muscle from different myotomes (Bergman et al.). The supraclavicularis muscle arises from the manubrium behind the sternocleidomastoideus muscle and passes behind the sternocleidomastoideus muscle to the upper surface fot he clavicle.
In our present findings, of the additional slip in the clavicular origin of sternocleidomastoid muscle may be due to abnormal splitting in the mesoderm of post-sixth branchial arch. However, the relevance of our findings whether it is associated with the condition of wry neck and other congenital deformities of the neck needs to be evaluated by further studies.

In our study, even though additional slip of origin was found on both sides, in the clavicular head of sternocleidomastoid muscle, we did not find any noticeable clinical symptoms. It is essential for the surgeons to be aware of possible variations during routine head and neck surgeries.

Knowledge of sternocleidomastoid muscle consists of additional parts and the muscle fibers in each part are lying in the same direction from origin to insertion in the same fascial package may be important for harvesting the muscle flap reconstruction during parotid surgery is an effective method of covering the surgical defect and possibly preventing Frey's syndrome. Thus, it would be possible to choose more appropriate muscle parts.

RAMESH, R. T.; VISHNUMAYA, G.; PRAKASHCHANDRA, S. K. \& SURESH, R. Variación en el origen del músculo esternocleidomastoideo. Reporte de caso. Int. J. Morphol., 25(3):621-623, 2007.

RESUMEN: Durante una disección de rutina, fue encontrado un raro caso de un fascículo adicional en el origen de la cabeza clavicular del músculo esternocleidomastoideo, en ambos lados del cuello, en un cadáver de un anciano de sexo masculino. Sin embargo, en ambos lados, no se encontró un fascículo adicional en el origen de la cabeza esternal ni en la inserción del músculo esternocleidomastoideo.

PALABRAS CLAVE: Músculo esternocleidomastoideo; Variación anatómica.

\section{REFERENCES}

Bergman, R. A.; Thomson, S. A. et al. Compendium of Anatomic Variation, In: Muscles, Urban and Schwarzenber, Baltimore, 1988. pp. 32-3.

Standring, S.; Berkovitz, B. K. B.; Hackney, C. M.; Ruskell, I. G. L. Gray's Anatomy. The Anatomical Basis of clinical practice. $39^{\text {th }}$ Churchill \& Livingtone, Edinburg, 2005. p. 536.

Williams, P. L.; Bannister, L. H.; Berry, M. et al. Gray's Anatomy. In: Muscle. Edited by Stanley Solomons. $38^{\text {th }}$ Churchill Livingestone, Edinburg, 1995. pp. 804-5.

Mustafa, M. A. Neuroanatomy. $10^{\text {th }}$ National Congress of Anatomy Bordum, Turkey, September 5:6-10, 2006.
Correspondence to:

Dr. T. Ramesh Rao

Department of Paraclinical Sciences

Faculty of Medical Sciences

The University of the West Indies

St. Augustine, TRINIDAD

Telephone: 1-868-645-2640 ext: 5005 (off) 1-868-3691431 (Cell)

Fax: $\quad 1-868-662-9148$

Email:varun1195@yahoo.com

Received: 08-03-2007

Accepted: 11-06-2007 
